\title{
Clinically Non-Functioning Pituitary Macroadenomas: Presenting Features and Outcomes - Recent Experience at a Tertiary Centre
}

\author{
Mahender Yadagiri ${ }^{1}$, Arun Vijay ${ }^{1}$, Mark Pritchard ${ }^{1}$, Ananth Nayak ${ }^{1}$, Simon Shaw ${ }^{2}$, \\ Natarajan Saravanappa ${ }^{3}$, John Ayuk ${ }^{1}$, Biju Jose ${ }^{1}$ \\ Depts. of Diabetes \& Endocrinology ${ }^{1}$, Neurosurgery ${ }^{2}$, ENT ${ }^{3}$ \\ Royal Stoke University Hospital, Stoke-on-Trent, UK
}

\section{Introduction}

Non-functioning pituitary macroadenoma (NFMA) can cause considerable morbidity due to pituitary dysfunction and pressure effects. Prevalence of pituitary adenoma is $80-100$ cases per 100,000 of the population; of these NFMA accounts for $15-30 \%$. Annual incidence is one per 100,000 of population $^{12}$

We present recent experience in managing NFMA at a single tertiary centre between January 2009 and Oct 2013.

\section{Results}

Of the 63 patients with NFMA, 28 (44\%) were females. Age ranged from 22 to 91 (mean-63).

The commonest presentations are shown below .

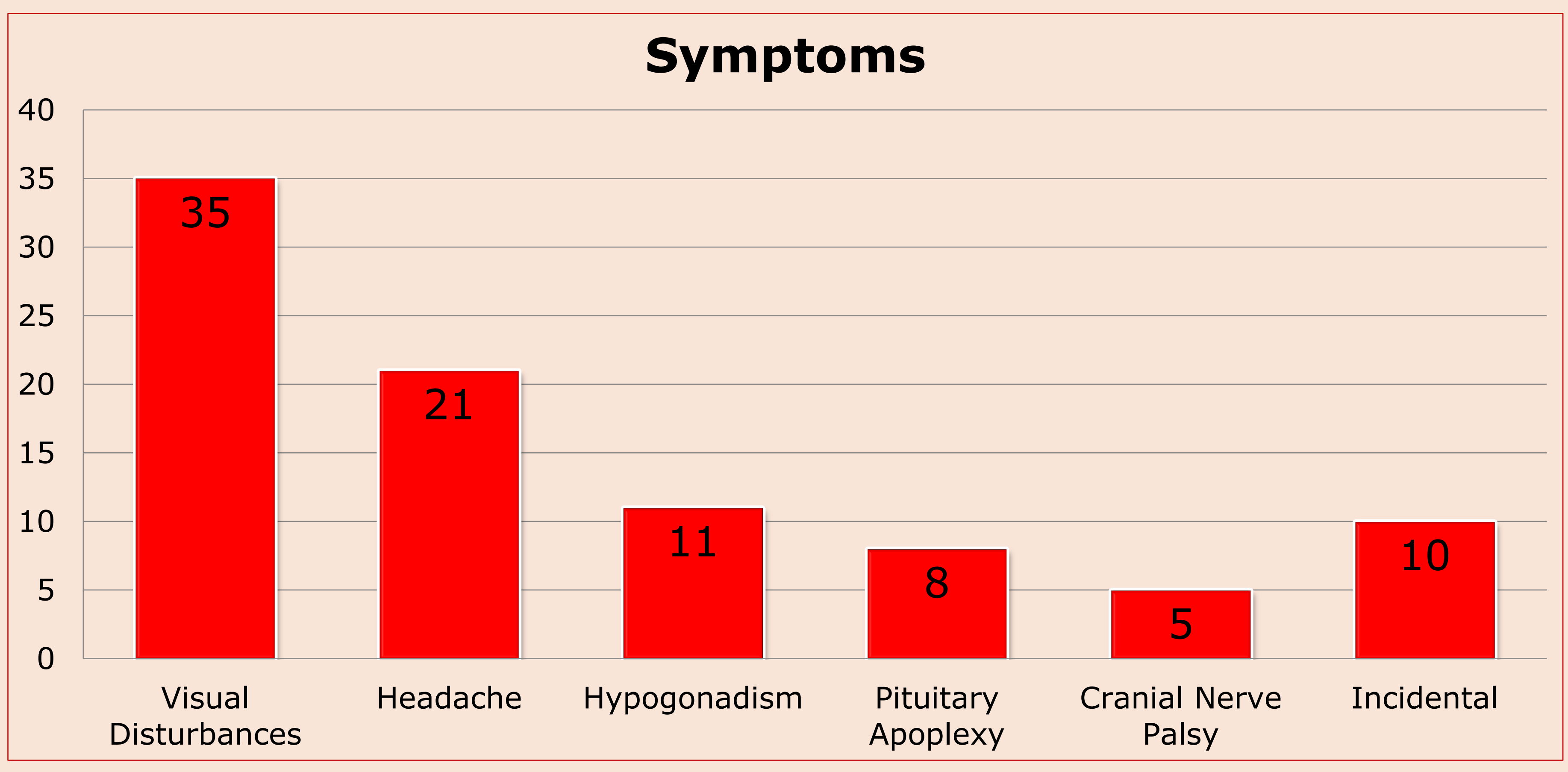

Prolactin levels ranged from 25 to $2536 \mathrm{mU} / \mathrm{l}$ (mean-394). Six patients $(10 \%)$ were found hypothyroid at presentation. Pituitary MRI scan showed elevation or compression of optic chiasm in 55 patients (87\%).

49 (78\%) underwent endoscopic trans-sphenoidal hypophysectomy. Three patients $(5 \%)$ required surgery for further tumour enlargement during follow-up.
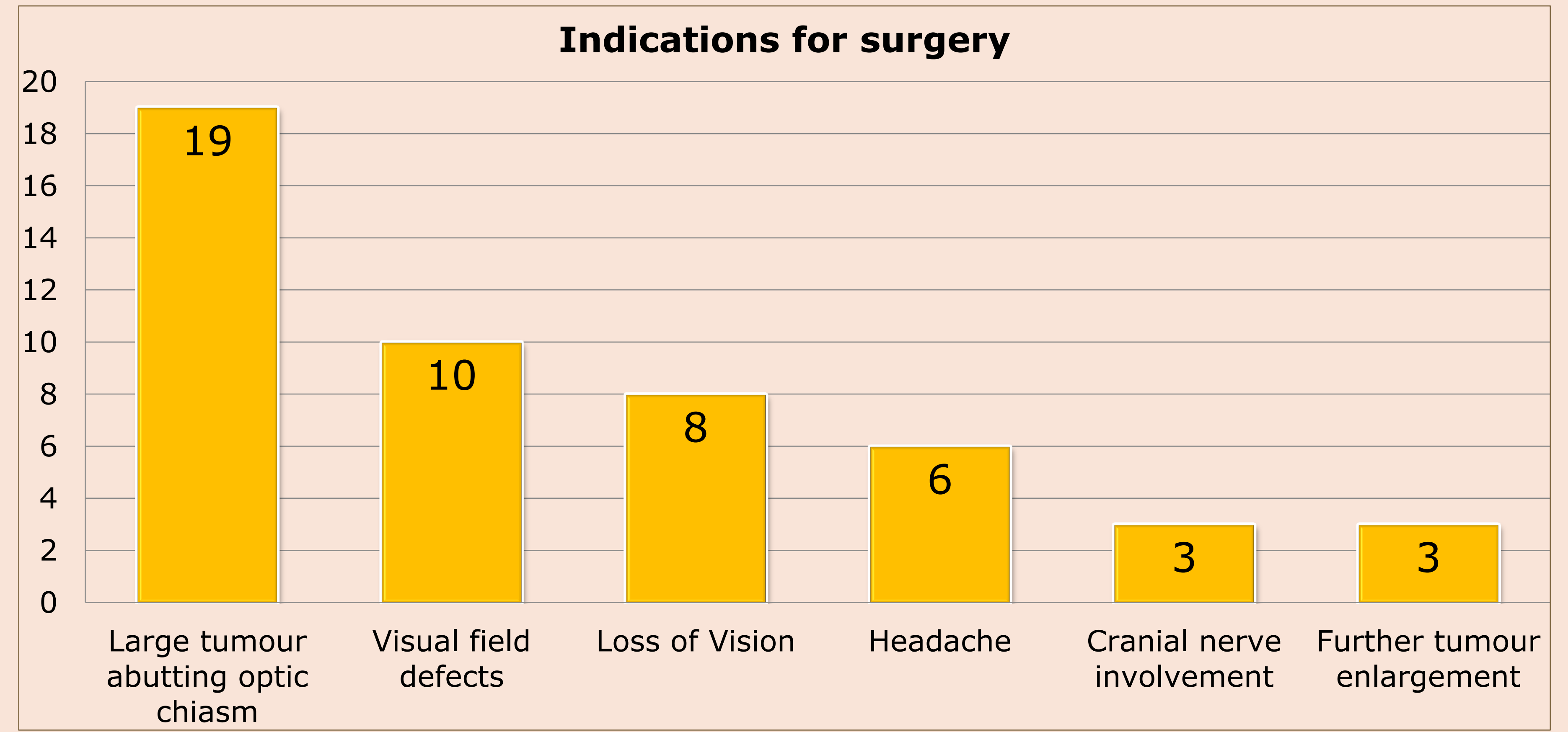

Post-operative complications included transient diabetes insipidus $(5 / 49 ; 10 \%)$, CSF leak $(2 / 29 ; 4 \%)$ and haemorrhage $(1 / 49 ; 2 \%)$.

Post-operatively, hormone replacement was required as shown below.

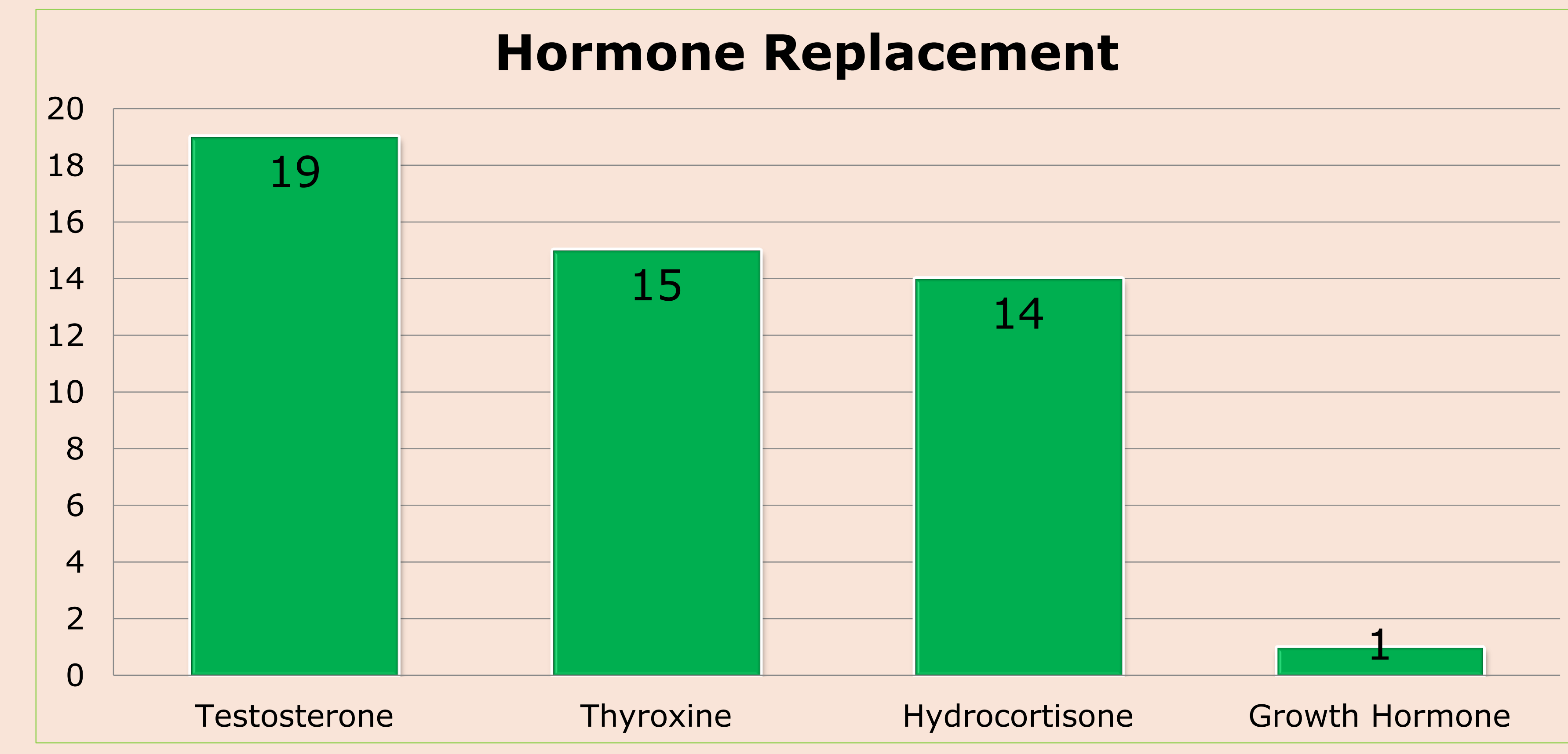

Patients with apoplexy had emergency surgery $(n=2)$, elective surgery $(n=4)$ and conservative management $(n=2)$. Five patients had improved vision following surgery, while one patient undergoing surgery after a year had no visual recovery.

\section{Conclusions}

NFMAs represent the bulk of patients presenting with a pituitary tumour. The clinical presentation can vary widely from asymptomatic incidental finding to catastrophic pituitary apoplexy as seen in this series.

Majority of NFMAs require surgery. A select subset can be managed conservatively. However these patients require long-term follow-up to monitor for tumour growth.

Appropriate and timely surgery can be crucial in patients presenting with apoplexy and should be considered in those with neuro-ophthalmic signs.

Post-operative hormone replacement is required in significant proportion of patients.

\section{References}

1. Raappana A et al- Incidence of pituitary adenomas in Northern Finland in 1992-2007. J Clin Endocrinol Metab2010;95(9):4268-75

2. Fernandez A, Karavitaki N, Wass JA. Prevalence of pituitary adenomas:a community-based, cross-sectional study in Banbury (Oxfordshire, UK).Clin Endocrinol (Oxf) 2010;72(3):377-82. 